\title{
ANALISIS TINGKAT KERENTANAN PENCEMARAN AIR TANAH PADA WILAYAH PENAMBANGAN DAN PENGOLAHAN EMAS RAKYAT DESA PANCURENDANG, KABUPATEN BANYUMAS
}

\author{
Eni Muryani, Dayu Aviana Rahmah, Dian Hudawan Santoso* \\ Jurusan Teknik Lingkungan, Fakultas Teknologi Mineral, UPN "Veteran” Yogyakarta, \\ Jl. SWK 104 (Lingkar Utara), Condongcatur, Yogyakarta, 55283 \\ *Email: dian.hudawan@upnyk.ac.id
}

\begin{abstract}
ANALYSIS OF GROUNDWATER POLLUTION LEVEL IN MINING AND PROCESSING AREAS OF PANCURENDANG VILLAGE, DISTRICT OF BANYUMAS
\end{abstract}

Gold mining and processing activities have a large impact on the environment. Some mineworker immediately dispose of waste from gold processing into the environment. Therefore, analysis of the level of vulnerability of pollution is needed to determine the level of difficulty and ease of contaminants to affect groundwater quality. The purpose of this study was to analyze the level of vulnerability of groundwater pollution around the study area.The method used in this research is survey method and field mapping, sampling method: purposive sampling, laboratory analysis method, mathematical method, and descriptive evaluation method. The calculation to determine the level of vulnerability of pollution is the DRASTIC method for groundwater vulnerability with 7 parameters, namely groundwater depth, rainfall, aquifer type, soil texture, slope, slope, unsaturated zone type, and hydraulic conductivity.The results showed that the study area had 2 classifications of the level of vulnerability of groundwater pollution, the medium and high classification. Wastewater from gold processing activities above the hillside can potentially pollute groundwater and surface water if it is not managed properly. Areas that are in the same direction as groundwater flow and lower than pollutant sources will have greater potential to be polluted.

Keywords : DRASTIC, Pollution, Groundwater, Gold Mine

\section{PENDAHULUAN}

Saat ini kebutuhan logam dasar dan logam mulia di Indonesia semakin meningkat. Pemanfaatannya yang semakin meningkat menuntut adanya eksploitasi akan sumberdaya mineral, khususnya logam mulia dan logam dasar (Rosana, 2011). Usaha pertambangan, oleh sebagian masyarakat sering dianggap sebagai penyebab kerusakan dan pencemaran lingkungan. Sebagai contoh, kegiatan pertambangan emas skala kecil, pengolahan bijih dilakukan dengan proses amalgamasi dimana merkuri $(\mathrm{Hg})$ digunakan sebagai media untuk mengikat emas. Mengingat sifat merkuri yang berbahaya, maka penyebaran logam ini perlu diawasi agar penanggulangannya dapat dilakukan sedini mungkin secara terarah (Setiabudi, B.T., 2005).

Proses amalgamasi sering digunakan karena metodenya sederhana dan biayanya relatif lebih murah dibandingkan dengan proses lainnya (Alimano, Marsen 2011). Merkuri dalam bentuk metil merkuri dapat terserap oleh makhluk hidup hingga $95 \%$. Apabila merkuri sudah masuk ke dalam tubuh berpotensi menyebabkan kerusakan pada organ pencernaan, hati, limfa, ginjal, syaraf yang dapat menyebabkan mati rasa, dan kehilangan keseimbangan (Alimano dan Darmutji, 2007).

Penambangan emas oleh rakyat sudah banyak dilakukan sebagaimana seperti penambangan emas oleh rakyat yang terdapat di Desa Pancurendang. Kegiatan penambangan emas dilakukan dengan 
membuat lubang tambang dalam bentuk sumur vertikal maupun horizontal di sekitar sungai dekat dengan areal ladang dan pemukiman warga. Pengolahan emas dilakukan di sekitar halaman rumah warga. Alat pengolahan emas hampir dapat ditemukan di seluruh rumah warga Desa Pancurendang.

Pencemaran lingkungan yang dapat terjadi akibat penyebaran merkuri adalah pencemaran air tanah dan air permukaan. Beberapa warga Desa Pancurendang masih membuang limbah hasil pengolahan emas langsung ke lingkungan, sehingga perlu adanya penelitian tentang tingkat kerentanan pencemaran pada air tanah. Tingkat kerentanan pencemaran pada air tanah dirasa penting untuk diteliti karena sebagian besar warga di daerah menggunakan air tanah sebagai sumber utama air minum dan kebutuhan domestik. Oleh karena itu tujuan peneitian ini adalah untuk menganlaisis seberapa besar tingkat kerentanan air tanah disekitar daerah penelitian.

\section{METODOLOGI}

\subsection{Pengumpulan Data}

Data yang dikumpulkan berupa data primer dan data sekunder. Data sekunder meliputi peta citra google earth, peta Rupa Bumi Indonesia, peta geologi regional dan peta jenis tanah, curah hujan, data bor daerah penelitian, dan monografi desa. Data primer berupa kedalaman muka air tanah, kualitas air tanah, kemiringan lereng, konduktivitas hidrolika, tekstur tanah dsb. Pengambilan sampel data primer dilakukan dengan teknik purposive sampling. Metode survei dan pengamatan digunakan sebagai metode untuk pembuatan beberapa jenis peta diantaranya peta kemiringan lereng dan penggunaan lahan.

\subsection{Uji Laboratorium}

Pengujian sampel air tanah dilakukan di laboratorium. Pengujian air tanah dilakukan dengan parameter merkuri $(\mathrm{Hg})$ dengan metode Mercury Analyzer. Pengujian kualitas air dilakukan di Laboratorium Penelitian dan Pengujian Terpadu Universitas Gadjah Mada. Hasil dari pengujian kualitas air ini kemudian disesuaikan dengan baku mutu dari peraturan terkait. Baku mutu merkuri $(\mathrm{Hg})$ dalam air tanah sebesar $0,001 \mathrm{mg} / \mathrm{L}$ mengacu pada Peraturan Menteri Kesehatan Nomor 492/MenKes/Per/IV/2010 Tentang Persyaratan Kualitas Air Minum.

\subsection{Pengolahan Data dan Analisis}

Metode yang digunakan untuk perhitungan tingkat kerentanan pencemaran air tanah adalah metode DRASTIC. Metode DRASTIC merupakan salah satu teknik PCSM (point count system models). Metode ini sering pula disebut sebagai metode pembobotan dan penilaian (parameter weighting and rating method). Parameter yang digunakan dalam pengklasifikasian tingkat kerentanan air tanah ialah kedalaman air tanah, laju pengisian kembali/curah hujan, media akuifer, media tanah, kemiringan lereng, dampak terhadap zona vadose, dan konduktivitas hidrolik akuifer.

Untuk mendapatkan tingkat kerentanan dengan metode DRASTIC, maka dapat dihitung dengan rumus sebagai berikut Kerentanan $=$

$D_{R} D_{W}+R_{R} R_{W}+A_{R} A_{W}+S_{R} S_{W}+T_{R} T_{W}+I_{R} I_{W}+C_{R} C_{W}$

$(\mathrm{R})=$ nilai untuk masing-masing parameter

$(\mathrm{w})=$ bobot untuk masing-masing paramete 
Tabel 1. Pembobotan Parameter Kerentanan dalam DRASTIC

\begin{tabular}{cclc}
\hline No. & & \multicolumn{1}{c}{ Parameter } & Bobot \\
\hline 1. & D & Depth to water table / kedalaman muka air tanah & 5 \\
2. & R & Recharge / curah hujan & 4 \\
3. & A & Aquifer medial / jenis akuifer & 3 \\
4. & S & Soil media / tekstur tanah & 2 \\
5. & T & Topography / kemiringan lereng & 1 \\
6. & I & Impact of vadose zone media / jenis zona tak jenuh & 5 \\
7. & C & Conductivity hydraulic / konduktivitas hidrolik akuifer & 3 \\
\hline
\end{tabular}

Sumber: Aller et aldrr., 1987 dalam Gunawan, 2012

Setelah mendapatkan data primer dan data sekunder untuk perhitungan metode DRASTIC, maka data tersebut dicocokan dengan kelas pada setiap parameter dari metode DRASTIC. Setiap kelas memiliki nilai yang berbeda sesuai dengan tinggi pengaruhnya terhadap nilai kerentanan pencemaran air permukaan.

Tabel 2. Kelas Kedalaman Air tanah

\begin{tabular}{cc}
\hline $\begin{array}{c}\text { Interval Kedalaman } \\
\text { Muka Air tanah } \\
\text { (meter) }\end{array}$ & Nilai \\
\hline $0-1,5$ & 10 \\
$1,5-4,6$ & 9 \\
$4,6-9,5$ & 7 \\
$9,5-15,2$ & 5 \\
$15,2-22,9$ & 3 \\
$22,9-30,5$ & 2 \\
$>30,5$ & 1 \\
\hline
\end{tabular}

Sumber: Aller et aldrr., 1987 dalam Gunawan, 2012

Tabel 3. Kelas Laju Pengisian Kembali

\begin{tabular}{cc}
\hline $\begin{array}{c}\text { Curah Hujan } \\
(\mathbf{m m} / \text { thn })\end{array}$ & Nilai \\
\hline $0-1500$ & 2 \\
$1500-2000$ & 4 \\
$2000-2500$ & 6 \\
$2500-3000$ & 8 \\
$>3000$ & 10 \\
\hline
\end{tabular}

Sumber: Alfiyan, 2011 dalam Gunawan, 2012
Tabel 4. Kelas Jenis Akuifer

\begin{tabular}{lc}
\hline \multicolumn{1}{c}{ Jenis Media Akuifer } & Nilai \\
\hline Serpih massif/besar & 1 \\
Batuan beku/malihan & 3 \\
Lapukan batuan beku/malihan & 4 \\
Sungai Es & 5 \\
Endapan batupasir, gamping, & 6 \\
dan rangkaian serpih & \\
Batugamping massif & 6 \\
Pasir dan kerikil & 8 \\
Basalt & 9 \\
Batugamping karst & 10 \\
\hline
\end{tabular}

Sumber: Aller et aldrr., 1987 dalam Gunawan, 2012

Tabel 5. Kelas Tekstur Tanah

\begin{tabular}{lc}
\hline \multicolumn{1}{c}{ Tekstur Tanah } & Nilai \\
\hline Kerikil & 10 \\
Pasir & 9 \\
Agregat/ perkerutan lempung & 7 \\
Lempung pasiran & 6 \\
Lempung & 5 \\
Lempung lanauan & 4 \\
Lempung liat & 3 \\
Campuran & 2 \\
Lempung non agregat & 1 \\
\hline
\end{tabular}

Sumber: Aller et aldrr., 1987 dalam Gunawan, 2012

Tabel 6. Kelas Kemiringan Lereng

\begin{tabular}{cc}
\hline Kemiringan Lereng & Nilai \\
$(\mathbf{\%})$ & \\
$0-2$ & 10 \\
$2-6$ & 9 \\
$6-12$ & 5 \\
$12-18$ & 3 \\
$>18$ & 1
\end{tabular}

Sumber: Aller et aldrr., 1987 dalam Gunawan, 2012 
Tabel 7. Kelas Jenis Zona Tak Jenuh

\begin{tabular}{lc}
\multicolumn{1}{c}{ Jenis Zona Tak Jenuh } & Nilai \\
\hline Lapisan pengikat & 1 \\
Lempung/ lanau & 3 \\
Serpih & 3 \\
Batugamping & 6 \\
Endapan batupasir, gamping, dan serpih & 6 \\
Pasir dan kerikil tercampur lempung dan & 6 \\
lanau & \\
Batuan malihan/ batuan beku & 4 \\
Pasir dan kerikil & 8 \\
Basal & 9 \\
Batugamping kars & 10 \\
\hline
\end{tabular}

Sumber: Aller et aldrr., 1987 dalam Gunawan, 2012

Tabel 8. Kelas Konduktivitas Hidraulik

\begin{tabular}{cc}
\hline $\begin{array}{c}\text { Interval Konduktivitas } \\
\text { Hidraulik (m/hari) }\end{array}$ & Nilai \\
\hline $0-0,86$ & 1 \\
$0,86-2,59$ & 2 \\
$2,59-6,05$ & 4 \\
$6,05-8,64$ & 6 \\
$8,64-17,18$ & 8 \\
$>17,18$ & 10 \\
\hline
\end{tabular}

Sumber: Widyastuti dkk, 2006 dalam

Gunawan, 2012

\subsection{Penentuan Indeks Kerentanan}

Penjumlahan hasil kali parameter DRASTIC menghasilkan Indeks DRASTIC yang mencerminkan kerentanan statis.
Kriteria tingkat kerentanan pencemaran dapat dilihat pada Tabel 9.

Tabel 9. Kriteria Tingkat Kerentanan Pencemaran Indeks DRASTIC

\begin{tabular}{lc}
\hline \multicolumn{1}{c}{$\begin{array}{c}\text { Tingkat } \\
\text { Kerentanan }\end{array}$} & Indeks DRASTIC \\
\hline Rendah & $1-100$ \\
Sedang & $100-140$ \\
Tinggi & $141-200$ \\
Sangat tinggi & $>200$ \\
\hline Sumber : Alfiyan, 2011 dalam Gunawan, \\
2012
\end{tabular}

\section{HASIL DAN PEMBAHASAN}

\subsection{Kondisi Kedalaman Muka Air Tanah}

Kedalaman muka air tanah didapat dengan mengukur jarak minimum muka air tanah terhadap permukaan. Menurut metode DRASTIC kedalaman muka air tanah memiliki nilai bobot 5. Pengukuran dilakukan terhadap 9 sumur penduduk. Berdasarkan hasil pengukuran di lapangan, kedalaman muka air tanah di daerah penelitian berkisar antara 1,5 sampai 8,2 meter. Menurut klasifikasi DRASTIC kedalaman muka air tanah di daerah penelitian dibagi menjadi 2 interval kedalaman muka air tanah, yaitu kedalaman air tanah 1,5-4,5 meter dengan nilai 9 dan kedalaman air tanah 4,5-9,5 dengan nilai 7.

Tabel 10.Nilai untuk kedalaman air tanah Metode DRASTIC

\begin{tabular}{cccccc}
\hline $\mathbf{X}$ & $\mathbf{Y}$ & $\begin{array}{c}\text { Kedalaman muka } \\
\text { air tanah }(\mathbf{m})\end{array}$ & Nilai & Bobot & $\begin{array}{c}\text { Total } \\
\text { (Nilai X Bobot) }\end{array}$ \\
\hline 288972 & 9179601 & 1.5 & 9 & 5 & 45 \\
288908 & 9179376 & 6.4 & 7 & 5 & 35 \\
289236 & 9179157 & 3.8 & 9 & 5 & 45 \\
288745 & 9179430 & 5.2 & 7 & 5 & 35 \\
289354 & 9179555 & 8.2 & 7 & 5 & 35 \\
289727 & 9179446 & 7.9 & 7 & 5 & 35 \\
289683 & 9179028 & 4.5 & 9 & 5 & 45 \\
288912 & 9179417 & 7.8 & 7 & 5 & 35 \\
289089 & 9179777 & 3.7 & 9 & 5 & 45 \\
\hline
\end{tabular}

Sumber : Data Lapangan, 2019

Nilai pembobotan kedalaman muka air tanah adalah 5 dan merupakan nilai bobot tertinggi dari nilai bobot parameter tingkat kerentanan lainnya. Kedalaman air tanah menjadi penting karena menyangkut ketebalan atau jarak yang harus ditempuh oleh kontaminan sebelum mencapai air tanah. Jarak tersebut dapat menentukan lamanya waktu kontak antara tanah dengan kontaminan. Faktor ini merupakan faktor 
yang penting karena sebelum mencapai muka air tanah, kontaminan harus melewati tebal lapisan di atas muka air tanah. Semakin dalam muka air tanah maka potensi kontaminasi air tanah akan semakin kecil, begitu juga sebaliknya bila muka air tanah semakin dangkal maka potensi kontaminasi air tanah akan semakin besar. Hal ini terbukti dengan mencapai muka air tanah akan semakin lama sehingga potensi kontaminasi juga akan semakin kecil.

\subsection{Kondisi Curah Hujan}

Tabel 11. Nilai untuk curah hujan Metode DRASTIC

\begin{tabular}{cccccc}
\hline $\mathbf{X}$ & $\mathbf{Y}$ & $\begin{array}{c}\text { Curah Hujan } \\
(\mathbf{m m} / \text { thn) }\end{array}$ & Nilai & Bobot & $\begin{array}{c}\text { Total } \\
\text { (Nilai x Bobot) }\end{array}$ \\
\hline 288972 & 9179601 & $3000-3100$ & 10 & 4 & 40 \\
288908 & 9179376 & $3000-3100$ & 10 & 4 & 40 \\
289236 & 9179157 & $3000-3100$ & 10 & 4 & 40 \\
288745 & 9179430 & $3000-3100$ & 10 & 4 & 40 \\
289354 & 9179555 & $3000-3100$ & 10 & 4 & 40 \\
289727 & 9179446 & $3000-3100$ & 10 & 4 & 40 \\
289683 & 9179028 & $3000-3100$ & 10 & 4 & 40 \\
288912 & 9179417 & $3000-3100$ & 10 & 4 & 40 \\
289089 & 9179777 & $3000-3100$ & 10 & 4 & 40 \\
\hline
\end{tabular}

Sumber : Data Lapangan, 2019

Jumlah curah hujan menggambarkan jumlah air yang jatuh ke permukaan tanah yang kemudian meresap ke dalam tanah untuk mencapai muka air tanah. Curah hujan ini mampu membantu transport kontaminan secara vertikal menuju muka air tanah serta secara horizontal di dalam akuifer. Hal tersebut mengontrol volume air yang mengandung kontaminan untuk mengalir pada daerah jenuh maupun tak jenuh. Secara umum, bila jumlah pengisian (recharge) air semakin besar, maka potensi kontaminasi air tanah akan semakin besar, begitu pula jika jumlah recharge air semakin sedikit, maka
Berdasarkan hasil analisis peta curah hujan wilayah yang bersumber dari data curah hujan pada 3 stasiun curah hujan terdekat dari daerah penelitian, maka curah hujan di daerah penelitian berkisar 3000-3100 mm/tahun yang termasuk kategori curah hujan tinggi. Menurut metode DRASTIC curah hujan memiliki nilai bobot 4. Tingkat curah hujan tinggi berpengaruh terhadap pencemaran air tanah karena pengenceran oleh air hujan maka menyebabkan kontaminan mudah terlarut dan bergerak menuju air tanah bebas. potensi kontaminasi air tanah akan semakin kecil (Triatmodjo, 2008).

\subsection{Jenis Akuifer}

Data parameter jenis akuifer diperoleh dari data bor yang terdapat di daerah penelitian. Daerah penelitian memiliki akuifer bebas yang tersusun oleh batupasir yang memiliki kadar besi tinggi dengan kedalaman berkisar 6 meter sampai 18 meter. Menurut metode DRASTIC media akuifer memiliki nilai bobot 3 . 
Tabel 12. Nilai untuk jenis akuifer Metode DRASTIC

\begin{tabular}{cccccc}
\hline $\mathbf{X}$ & $\mathbf{Y}$ & Jenis Media Akuifer & Nilai & Bobot & $\begin{array}{c}\text { Total } \\
\text { (Nilai X Bobot) }\end{array}$ \\
\hline 288972 & 9179601 & Batupasir & 6 & 3 & 18 \\
288908 & 9179376 & Batupasir & 6 & 3 & 18 \\
289236 & 9179157 & Batupasir & 6 & 3 & 18 \\
288745 & 9179430 & Batupasir & 6 & 3 & 18 \\
289354 & 9179555 & Batupasir & 6 & 3 & 18 \\
289727 & 9179446 & Batupasir & 6 & 3 & 18 \\
289683 & 9179028 & Batupasir & 6 & 3 & 18 \\
288912 & 9179417 & Batupasir & 6 & 3 & 18 \\
289089 & 9179777 & Batupasir & 6 & 3 & 18 \\
\hline
\end{tabular}

Sumber : Data Lapangan, 2019

Media akuifer dengan butiran yang besar menunjukkan kerentanan pencemaran air tanah sangat rentan. Kontaminan di akuifer bergantung pada jumlah dan kehalusan akuifer secara umum. Ukuran butir besar mengakibatkan permeabilitas tinggi dan kapasitas rendah sehingga meningkatkan kerentanan pencemaran air tanah (Diva, 2018).

Media akuifer menunjukkan kekompakkan dan ketidakkompakkan batuan dalam menyimpan air tanah. Akuifer merupakan formasi batuan yang dapat menghasilkan air dalam kuantitas cukup. Media akuifer juga mempengaruhi jumlah dari material permukaan yang terkontaminasi dalam menembus lapisan akuifer. Semakin besar kemampuan akuifer untuk menahan kontaminan maka waktu tempuh pergerakan kontaminan akan semakin lama sehingga potensi kontaminasi air tanah akan semakin kecil (Diva, 2018).

\subsection{Tekstur Tanah}

Parameter tekstur tanah berhubungan dengan jenis tanah. Penentuan jenis tanah didapat dari pengamatan dan pemetaan di lapangan. Nilai bobot tekstur tanah untuk tingkat kerentanan adalah 2. Hasil dari pengamatan dan pemetaan di lapangan dapat diketahui bahwa daerah ini didominasi oleh lempung. Tekstur jenis tanah lempung mempunyai potensi kerentanan yang lebih rendah terhadap pencemaran karena daya resap air hujan lebih lambat daripada pasir.

Tabel 13. Nilai untuk tekstur tanah Metode DRASTIC

\begin{tabular}{cccccc}
\hline $\mathbf{X}$ & $\mathbf{Y}$ & Tekstur Tanah & Nilai & Bobot & $\begin{array}{c}\text { Total } \\
\text { (Nilai x Bobot) }\end{array}$ \\
\hline 288972 & 9179601 & Lempung & 5 & 2 & 10 \\
288908 & 9179376 & Lempung & 5 & 2 & 10 \\
289236 & 9179157 & Lempung & 5 & 2 & 10 \\
288745 & 9179430 & Lempung & 5 & 2 & 10 \\
289354 & 9179555 & Lempung & 5 & 2 & 10 \\
289727 & 9179446 & Lempung & 5 & 2 & 10 \\
289683 & 9179028 & Lempung & 5 & 2 & 10 \\
288912 & 9179417 & Lempung & 5 & 2 & 10 \\
289089 & 9179777 & Lempung & 5 & 2 & 10 \\
\hline
\end{tabular}

Sumber : Data Lapangan, 2019

Tanah mempunyai dampak langsung dan sangat signifikan dari jumlah menyimpan air yang meresap ke dalam tanah hingga mencapai muka air tanah dan juga mempengaruhi pergerakan kontaminan. Kemampuan dari material tanah dengan tekstur yang halus, seperti lanau dan lempung akan membatasi pergerakan kontaminan. Semakin kasar tekstur tanah maka tingkat infiltrasi semakin tinggi sehingga kerentanan air tanah semakin tinggi. Ketebalan tanah juga mempengaruhi waktu tempuh kontaminasi 
Semakin tebal tanah maka waktu tempuh kontaminasi juga semakin lama (Diva, 2018).

\subsection{Kemiringan Lereng}

Parameter kemiringan lereng didapat dari kontur peta topografi daerah penelitian dan klasifikasi Van Zuidam. Nilai bobot kemiringan lereng untuk tingkat kerentanan adalah 1. Daerah penelitian memenuhi 4 klasifikasi Van Zuidam. Kemiringan lereng datar $(0-2 \%)$ terletak di bagian barat daerah penelitian dan memenuhi $20 \%$ dari daerah penelitian. Kemiringan lereng agak curam (15-30\%) terletak di bagian timur daerah penelitian dan memenuhi $10 \%$ dari daerah penelitian. Kemiringan lereng curam (30$70 \%$ ) mendominasi daerah penelitian dan memenuhi $60 \%$ dari daerah penelitian. Kemiringan lereng terjal (70-140\%) terletak di bagian tenggara dan barat daya daerah penelitian dan memenuhi $10 \%$ dari daerah penelitian.

Tabel 14. Nilai untuk kemiringan lereng Metode DRASTIC

\begin{tabular}{cccccc}
\hline $\mathbf{X}$ & $\mathbf{Y}$ & $\begin{array}{c}\text { Kemiringan Lereng } \\
(\boldsymbol{\%})\end{array}$ & Nilai & Bobot & $\begin{array}{c}\text { Total } \\
\text { (Nilai x Bobot) }\end{array}$ \\
\hline 288972 & 9179601 & $0-2$ & 10 & 1 & 10 \\
288908 & 9179376 & $30-70$ & 1 & 1 & 1 \\
289236 & 9179157 & $70-140$ & 1 & 1 & 1 \\
288745 & 9179430 & $30-70$ & 1 & 1 & 1 \\
289354 & 9179555 & $15-30$ & 1 & 1 & 1 \\
289727 & 9179446 & $15-30$ & 1 & 1 & 1 \\
289683 & 9179028 & $30-70$ & 1 & 1 & 1 \\
288912 & 9179417 & $30-70$ & 1 & 1 & 1 \\
289089 & 9179777 & $30-70$ & 1 & 1 & 1 \\
\hline
\end{tabular}

Sumber : Data Lapangan, 2019

Daerah penelitian yang didominasi kemiringan lereng curam cenderung tidak menampung air dan memperbesar run-off, sehingga air tanah tidak mudah terkontaminasi. Sementara kemiringan lereng datar sehingga cenderung menampung air dan meningkatkan infiltrasi, sehingga membantu mempercepat pergerakan kontaminan. Prinsip gravitasi akan mempercepat pergerakan kontaminan (Sugianti, 2015). Daerah penelitian yang memiliki nilai besar merupakan daerah dengan kemiringan lereng datar dan terdapat kegiatan penambangan dan pengolahan emas.

\subsection{Zona Tak Jenuh}

Parameter zona tak jenuh didapatkan pengamatan di lapangan dan diperoleh dari data bor yang terdapat di daerah penelitian. Nilai bobot zona tak jenuh untuk tingkat kerentanan adalah 5. Parameter ini sangat berpengaruh terhadap pencemaran, yaitu zona tak jenuh yang berukuran butir tanah lebih besar dan kondisi tanah yang poros akan membantu bergeraknya kontaminan menuju akuifer (Sugianti, 2015).

Tabel 15. Nilai untuk zona tak jenuh Metode DRASTIC

\begin{tabular}{cccccc}
\hline $\mathbf{X}$ & $\mathbf{Y}$ & $\begin{array}{c}\text { Zona Tak } \\
\text { Jenuh }\end{array}$ & Nilai & Bobot & $\begin{array}{c}\text { Total } \\
\text { (Nilai } \mathbf{x} \\
\text { Bobot) }\end{array}$ \\
\hline 288972 & 9179601 & Lempung & 3 & 5 & 15 \\
288908 & 9179376 & Lempung & 3 & 5 & 15 \\
289236 & 9179157 & Lempung & 3 & 5 & 15 \\
288745 & 9179430 & Lempung & 3 & 5 & 15 \\
289354 & 9179555 & Lempung & 3 & 5 & 15 \\
289727 & 9179446 & Lempung & 3 & 5 & 15 \\
289683 & 9179028 & Lempung & 3 & 5 & 15 \\
288912 & 9179417 & Lempung & 3 & 5 & 15 \\
289089 & 9179777 & Lempung & 3 & 5 & 15 \\
\hline
\end{tabular}

Sumber : Data Lapangan, 2019

Jenis media zona tak jenuh merupakan zona yang tidak jenuh air. Media ini terletak di bawah lapisan tanah permukaan dan di atas muka air tanah. Jenis media zona tak 
jenuh akan berpengaruh terhadap pergerakan air dari permukaan menuju muka air tanah, dimana kecepatan masuknya air akan sangat dipengaruhi oleh ukuran butir dari tanah atau batuan yang ada pada daerah tersebut.

\subsection{Konduktivitas Hidraulik}

Konduktivitas hidraulik adalah kemampuan akuifer untuk mengalirkan air yang bergantung permeabilitas instrinsik dari material dan tingkat kejenuhannya. Kedua 166isper tersebut mengendalikan perpindahan dan 166isperse kontaminan dari titik injeksi dalam zona jenuh (Alfiyan, 2011). Data konduktivitas hidraulik didapatkan dengan melakukan pumping test di sumur-sumur gali warga daerah penelitian. Menurut metode DRASTIC konduktivitas hidrolik memiliki nilai bobot 3 .

Pumping test dilakukan di 4 titik sumur air warga dan didapatkan nilai konduktivitas hidraulik yang tidak jauh berbeda. Nilai konduktivitas hidraulik daerah penelitian ialah 3,718 $\mathrm{m} /$ hari, 3,214 $\mathrm{m} /$ hari, 3,369 $\mathrm{m} /$ hari, dan 3,326 m/hari. Nilai konduktivitas daerah penelitian masuk ke klasifikasi 2,59 $6,05 \mathrm{~m} / \mathrm{hari}$. Titik sumur pumping test tersebar dan sudah mewakili daerah penelitian, sehingga nilai untuk daerah penelitian dianggap sama. Todd (1980) mengklasifikasikan nilai konduktivitas hidraulik berdasarkan material penyusun akuifernya. Nilai konduktivitas hidraulik daerah penelitian mendekati 3,1 $\mathrm{m} / \mathrm{hari}$ sehingga dapat diketahui material penyusun akuifernya adalah batupasir sedang dan tingkat permeabilitas (kemampuan untuk meloloskan air) tergolong sedang.

Tabel 16. Nilai untuk konduktivitas hidraulik Metode DRASTIC

\begin{tabular}{cccccc}
\hline $\mathbf{X}$ & $\mathbf{Y}$ & $\begin{array}{c}\text { Data } \\
(\mathbf{m} / \mathbf{h a r i})\end{array}$ & Nilai & Bobot & $\begin{array}{c}\text { Total } \\
\text { (Nilai } \mathbf{x} \\
\text { Bobot })\end{array}$ \\
\hline 288972 & 9179601 & 3,369 & 4 & 3 & 12 \\
288908 & 9179376 & & & & 12 \\
289236 & 9179157 & 3,718 & 4 & 3 & 12 \\
288745 & 9179430 & & & & 12 \\
289354 & 9179555 & & & & 12 \\
289727 & 9179446 & 3,214 & 4 & 3 & 12 \\
289683 & 9179028 & & & & 12 \\
\hline
\end{tabular}

\begin{tabular}{cccccc}
\hline $\mathbf{X}$ & $\mathbf{Y}$ & $\begin{array}{c}\text { Data } \\
(\mathbf{m} / \mathbf{h a r i})\end{array}$ & Nilai & Bobot & $\begin{array}{c}\text { Total } \\
\text { (Nilai } \mathbf{x} \\
\text { Bobot) }\end{array}$ \\
\hline 288912 & 9179417 & & & & 12 \\
289089 & 9179777 & 3,326 & 4 & 3 & 12 \\
\hline
\end{tabular}

Sumber : Data Lapangan, 2019

Konduktivitas hidraulik (K) atau sering disebut pula dengan permeabilitas merupakan kecepatan atau kemampuan lapisan batuan untuk meloloskan air. Permeabilitas ini dipengaruh oleh sifat fisik, yaitu porositas, ukuran butir, susunan butir, bentuk butir, dan distribusinya (Todd, 1980). Semakin besar permeabilitasnya maka karakteristik akuifer tersebut juga semakin baik karena air tanah mudah bergerak. Permeabilitas akuifer pada daerah penelitian tergolong sedang. Sesuai dengan material penyusun akuifernya yang berupa batupasir sedang, kemampuannya untuk meloloskan air tidak terlalu besar karena ukuran butir pasir sedang $(0,5-1 \mathrm{~mm})$ tersebut sehingga air yang tertampung dalam akuiferpun tidak terlalu banyak.

\subsection{Tingkat Kerentanan Pencemaran Air tanah Daerah Penelitian}

Daerah yang memiliki nilai indeks yang tinggi termasuk dalam daerah yang sangat rentan untuk terkena zat pencemar air tanah. Daerah yang memiliki nilai indeks rendah juga berpotensi terkena zat pencemar air tanah, namun tingkat kerentanannya masih lebih rendah dibandingkan daerah dengan skor tinggi. Semua parameter dilakukan tumpang susun (overlay) dengan menggunakan sistem informasi geografis (SIG). Hasil dari tumpang susun (overlay) dari setiap parameter tingkat kerentanan air tanah menunjukkan bahwa daerah penelitian memiliki 4 total skor yang berbeda dan masuk ke dalam 2 tingkat kerentanan yang berbeda. Total skor yang didapat ialah 150, 141, dan 131. Total skor 100-140 termasuk dalam indeks DRASTIC dengan tingkat kerentanan sedang. Total skor 141-200 termasuk dalam indeks DRASTIC dengan tingkat kerentanan tinggi. 


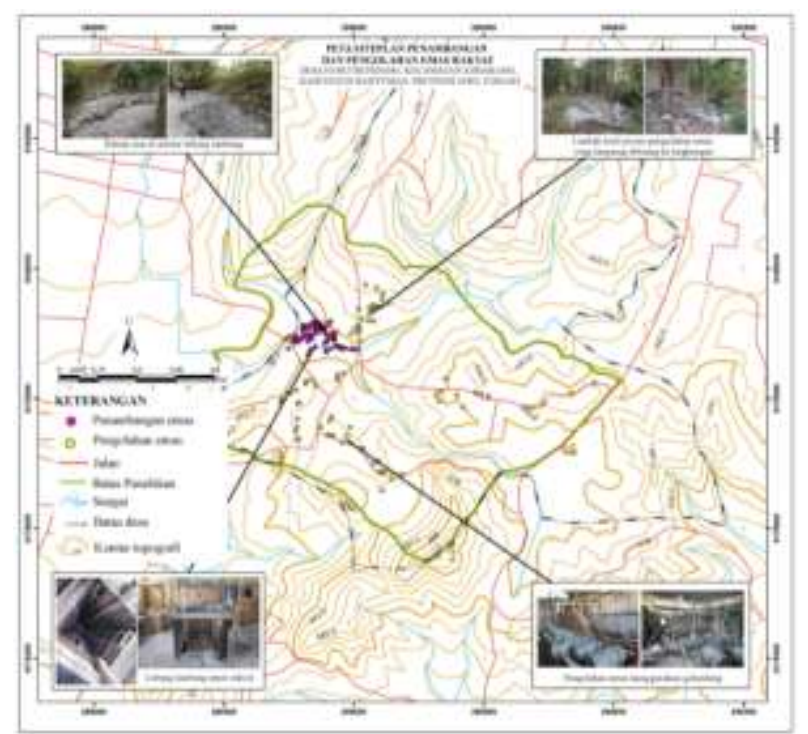

Gambar 1.

Peta Persebaran Penambangan Emas Rakyat di Daerah Penelitian

Daerah penelitian dengan tingkat kerentanan sedang memiliki interval kedalaman muka air tanah 4,6-9,5 meter, curah hujan 3000-3100 mm/tahun, jenis akuifer batupasir, tekstur tanah lempung, kemiringan lereng $0-2 \%$ dan $>18 \%$, zona tak jenuh lempung, dan memiliki interval konduktivitas hidraulik 2,59-6,05 m/hari. Daerah yang memiliki tingkat kerentanan sedang terletak di bagian timur daerah penelitian dan menempati $70 \%$ dari daerah penelitian. Daerah dengan tingkat kerentanan sedang merupakan daerah lereng perbukitan dan terdapat banyak sekali kegiatan pengolahan emas rakyat.
Daerah penelitian dengan tingkat kerentanan tinggi memiliki interval kedalaman muka air tanah 1,5-4,6 meter, curah hujan 3000-3100 mm/tahun, jenis akuifer batupasir, tekstur tanah lempung, kemiringan lereng $0-2 \%$ dan $>18 \%$, zona tak jenuh lempung, dan memiliki interval konduktivitas hidraulik 2,59-6,05 $\mathrm{m} / \mathrm{hari}$. Daerah yang memiliki tingkat kerentanan sedang terletak di bagian barat daerah penelitian dan menempati $30 \%$ dari daerah penelitian. Daerah dengan tingkat kerentanan tinggi merupakan daerah datar dan terdapat banyak sekali kegiatan penambangan emas dan pengolahan emas rakyat.

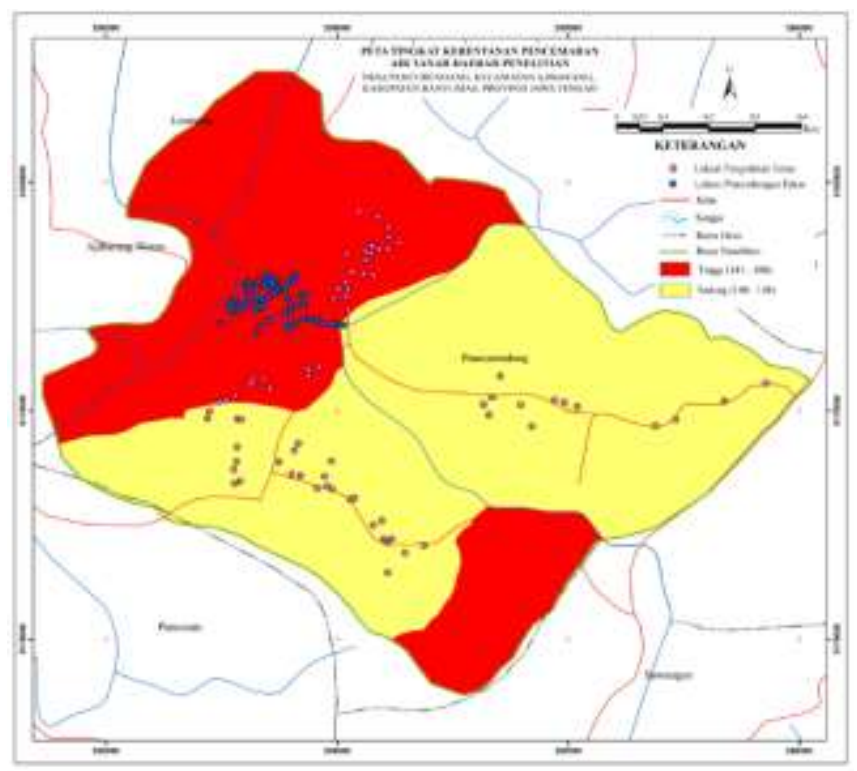

Gambar 2.

Peta Tingkat Kerentanan Air tanah di daerah penelitian 
Pemanfaatan air tanah pada daerah yang memiliki potensi kerentanan tinggi sebaiknya menggunakan air sumur dalam, dikarenakan tingginya potensi kontaminan ke dalam air sumur dangkal. Selain itu perlu dibuatkan suatu area khusus yang digunakan sebagai Instalasi Pengolahan Air Limbah (IPAL), sehingga limbah yang dihasilkan tidak langsung terinfiltrasi ke dalam tanah, namun diolah terlebih dahulu. Jika saran tersebut bisa dilakukan oleh pemerintah daerah, maka tingginya potensi kerentanan air tanah terhadap kontaminan diharapkan dapat dicegah (Gunawan, 2012).

Daerah penelitian yang memiliki tingkat kerentanan pencemaran tinggi merupakan daerah yang memiliki kedalaman muka air tanah dekat dengan permukaan tanah. Sehingga daerah tersebut harus dilakukan cara preventif agar zat pencemar yaitu merkuri $(\mathrm{Hg})$ tidak dapat meresap ke dalam tanah menuju air tanah. Selain itu lebih baik jika sumber pencemar tidak berada di daerah yang memiliki tingkat kerentanan pencemaran tinggi.

Kedalaman muka air tanah dan zona tak jenuh memberikan pengaruh yang paling besar terhadap tingkat kerentanan air tanah yang didapat karena memiliki bobot terbesar dari parameter lainnya. Nilai zona tak jenuh akan bernilai tinggi apabila zona tak jenuh memiliki porositas yang besar dan kemampuan mengalirkan air yang besar. Daerah penelitian memiliki zona tak jenuh berupa lempung sehingga tidak memiliki nilai yang tinggi untuk kerentanan air tanah. Porositas lempung lebih kecil daripada pasir sehingga dapat menghambat masuknya zat pencemar ke dalam air tanah.

Kualitas air tanah dan penggunaan lahan di atasnya terdapat korelasi. Perlindungan air tanah dari pencemaran menjadi penting terutama melihat begitu pesatnya pemanfaatan penggunaan lahan. Kualitas air tanah di daerah penelitian diambil di 3 titik yang berbeda.

Sampel air tanah 1 diambil di lubang tambang daerah penelitian pada koordinat $\mathrm{X}=289014$ dan $\mathrm{Y}=9179686$ dengan ketinggian 98 mdpl. Penambang akan mengeluarkan air tanah yang memenuhi lubang tambang setiap harinya sebelum pekerjaan penambangan dimulai. Sampel air tanah 2 diambil dari sumur pemukiman warga yang dekat dengan tempat pengolahan emas, yang terletak pada koordinat $\mathrm{X}=288916$ dan $\mathrm{Y}=9179428$ dengan ketinggian $131 \mathrm{mdpl}$. Sampel air tanah 3 diambil di sumur pemukiman warga yang jaraknya jauh dari tempat pengolahan emas, yang terletak pada koordinat $\mathrm{X}=289056$ dan $\mathrm{Y}=9179253$ dengan ketinggian $140 \mathrm{mdpl}$.

Tabel 17. Tabel Kualitas Air tanah

\begin{tabular}{ccccc}
$\begin{array}{c}\text { Nama } \\
\text { Sampel }\end{array}$ & pH & $\begin{array}{c}\text { Kadar } \\
\text { Merkuri } \\
(\mathbf{H g})\end{array}$ & $\begin{array}{c}\text { Baku } \\
\text { Mutu }\end{array}$ & Keterangan \\
\hline Air tanah 1 & 7 & $\begin{array}{c}0,00013 \\
\mathrm{mg} / \mathrm{L}\end{array}$ & $\begin{array}{c}0,001 \\
\mathrm{mg} / \mathrm{L}\end{array}$ & $\begin{array}{c}\text { Tidak melebihi } \\
\text { baku mutu }\end{array}$ \\
Air tanah 2 & 7 & $\begin{array}{c}0,00184 \\
\mathrm{mg} / \mathrm{L}\end{array}$ & $\begin{array}{l}0,001 \\
\mathrm{mg} / \mathrm{L}\end{array}$ & $\begin{array}{c}\text { Melebihi baku } \\
\text { mutu }\end{array}$ \\
Air tanah 3 & 7 & $\begin{array}{c}0,00013 \\
\mathrm{mg} / \mathrm{L}\end{array}$ & $\begin{array}{l}0,001 \\
\mathrm{mg} / \mathrm{L}\end{array}$ & $\begin{array}{c}\text { Tidak melebihi } \\
\text { baku mutu }\end{array}$ \\
\hline
\end{tabular}

Sumber : Data Lapangan, 2019

Baku mutu air tanah ialah $\mathrm{pH}$ 6,5-8,5 dan kadar merkuri $(\mathrm{Hg})$ sebesar 0,001 $\mathrm{mg} / \mathrm{L}$ mengacu pada Peraturan Menteri Kesehatan Nomor 492/MenKes/Per/IV/2010 Tentang Persyaratan Kualitas Air Minum.Arah aliran air tanah di daerah penelitian yaitu dari daerah yang memiliki elevasi tinggi ke daerah yang memiliki elevasi rendah. Sungai Datar yang terletak di bagian tengah daerah penelitian merupakan daerah yang memiliki elevasi paling rendah di daerah penelitian. Sehingga arah aliran air tanah akan menuju ke Sungai Datar yang merupakan bagian tengah daerah penelitian.

Limbah hasil kegiatan pengolahan emas yang berada di atas lereng bukit dapat berpotensi mencemari air tanah dan air permukaan apabila tidak dikelola dengan baik. Daerah yang letaknya searah dengan aliran air tanah dan lebih rendah dari sumber pencemar akan berpotensi lebih besar untuk tercemar. Semakin dekat jarak sumber ke muka air tanah, maka akan semakin tinggi potensi pencemaran.

Sampel air tanah 2 terletak di bagian tengah lereng bukit, dan bagian atas lereng bukit terdapat kegiatan pengolahan emas. Sehingga hasil sampel air tanah 2 yang melebihi baku mutu dipengaruhi oleh limbah 
hasil pengolahan emas. Keadaan ini sangat berbahaya karena masyarakat Desa Pancurendang masih menggunakan air tanah dari sumur untuk dikonsumsi dan kegiatan sehari-hari. Kandungan merkuri yang masuk ke dalam tubuh manusia dapat berdampak negatif bagi kesehatan. Apabila merkuri sudah masuk ke dalam tubuh berpotensi menyebabkan kerusakan pada organ pencernaan, hati, limfa, ginjal, syaraf yang dapat menyebabkan mati rasa, dan kehilangan keseimbangan (Alimano dan Darmutji, 2007).

\section{SIMPULAN DAN SARAN}

\subsection{Simpulan}

Berdasarkan hasil penelitian dapat disimpulkan bahwa daerah penelitian memiliki 2 klasifikasi tingkat kerentanan pencemaran air tanah, yaitu klasifikasi tingkat kerentanan sedang dan klasifikasi tingkat kerentanan tinggi, dimana total skor 100-140 termasuk dalam indeks DRASTIC dengan tingkat kerentanan sedang dan total skor 141200 termasuk dalam indeks DRASTIC dengan tingkat kerentanan tinggi.

\subsection{Saran}

Untuk mencegah terjadinya pencemaran air tanah yang lebih meluas hendaknya dilakukan pengendalian secara terpadu yang bisa dilakukan oleh pemerintah maupun oleh masyarakat penambang di daerah sekitar penambangan emas rakyat.

\section{DAFTAR PUSTAKA}

Alfiyan, M. 2011. Pengembangan Metode DRASTIC Untuk Analisis Tingkat Kerentanan (Vulnerability) Pencemaran Air tanah Calon Lokasi Landfill Tenorm. Prosiding Seminar Nasional Teknologi Pengelolaan Limbah IX: Fakultas Teknik Universitas Sultan Ageng Tirtayasa

Alimano, Marsen, M. Lutfi, Retno Dmayanti. 2011. Rancangan Pengolahan Limbah Pertambangan Emas Rakyat dengan
Eceng Goncok (Eichhornia crassipes) di Bolaang Mongondow. Jurnal Teknologi Mineral dan Batubara Volume 7, Nomor 3

Alimano, M. dan Darmutji S. 2007. Evaluasi Proses Amalgamasi Emas Terhadap Kesehatan Masyarakat. Jurnal Teknologi Mineral dan Batubara Nomor 40 Tahun 15. ISSN 0854-7890. Bandung. Hal 25-31

Diva, Nova Clara. 2018. Evaluasi Kerentanan Pencemaran Air Bawah Tanah Menggunakan Metode DRASTIC di Kabupaten Bogor. Skripsi Departemen Geofisika dan Meteorologi, Fakultas Matematika dan Ilmu Pengetahuan Alam, Institut Pertanian Bogor

Gunawan, Wayan Andi Frederich, Diang Sisinggih, dan Very Dermawan. 2012. Studi Kerentanan Air tanah terhadap Kontaminan di Cekungan Air tanah Negara Kabupaten Jembrana Provinsi Bali. Jurnal Pengairan Universitas Brawijaya Vol 4, No 2

Rosana, M.F. dkk. 2011. Mineralisasi Emas Epitermal di Daerah Sako Merah dan Manau, Jambi. Bionatura-Jurnal IlmuIlmu Hayati dan Fisik, 13 (2), 235-247

Setiabudi, B.T. 2005. Penyebaran Merkuri Akibat Usaha Pertambangan Emas di Daerah Sangon, Kabupaten Kulon Progo, Provinsi D.I. Yogyakarta. Kolokium Hasil Lapangan, Direktorat Inventarisasi Sumberdaya Mineral/DIM/2005

Sugianti, Khori, Dedi Mulyadi, Rizka Maria. 2015. Analisis Kerentanan Pencemaran Air tanah dengan Pendekatan Metode DRASTIC di Bandung Selatan. Jurnal Lingkungan dan Bencana Geologi. Pusat Penelitian Geoteknologi LIPIBandung

Todd, D.K., 1980, Groundwater Hydrology, John Wiley \& Sons, New York.

Triatmodjo, Bambang. 2008. Hidrologi

Terapan. Yogyakarta: Beta Offset 